\title{
Saber, poder e subjetividade no contexto canavieiro do Brasil
}

Knowledge, power and subjetivity in the sugarcane sector in Brazil

Conocimiento científico, poder y subjetividad en el contexto de la caña de azúcar de Brasil

\section{Paulo dos Santos Nascimento}

Universidade Federal de Alagoas, Maceió, AL, Brasil.

\section{Simone Maria Hüning}

Universidade Federal de Alagoas, Maceió, AL, Brasil.

\section{Resumo}

O objetivo desse artigo é analisar a produção acadêmica brasileira das ciências humanas e sociais, sobre modos de vida, trabalho e subjetivação no setor canavieiro do Brasil. Analisamos publicações científicas dos anos 2000-2010, em língua portuguesa, disponíveis na biblioteca eletrônica Scielo e no Banco de Teses da CAPES. A análise, sob uma perspectiva foucaultiana, foi estruturada em três eixos: ciência e cotidiano; resistência e submissão; subjetividade/subjetivação. Concluímos que a maior parte dessas produções filiam-se a tradições críticas; a objetivação dos sujeitos oscila entre descrições de passividade e de práticas autônomas de resistências; os estudos sobre subjetividade não fazem parte das publicações sobre o setor canavieiro. Indicamos a necessidade de ampliação desses estudos na Psicologia em uma perspectiva da epistemologia política.

Palavras-chave: ciências humanas e sociais; poder-saber; setor canavieiro; subjetividade.

\begin{abstract}
The aim of this paper is to analyze the Brazilian academic production of the humanities and social sciences, on lifestyle, work and subjectivity in the sugarcane sector in Brazil. We analyzed scientific publications of the years 2000-2010, in Portuguese, available in the electronic library SciELO and the CAPES Theses Database. The analysis, from a Foucauldian perspective, was structured in three axes: science and everyday life; resistance and submission; subjectivity/subjectification. We concluded that most of these productions are affiliated to critical traditions; the objectification of the individuals ranges from descriptions of passivity and autonomous practices of
\end{abstract}


resistance; the studies on subjectivity are not part of the publications on the sugarcane sector. We indicate the need to expand these studies in Psychology from a perspective of political epistemology.

Keywords: human and social sciences; power-knowledge; sugar cane sector; subjectivity.

\section{Resumen}

El objetivo de este trabajo es analizar la producción académica brasileña de las ciencias humanas y sociales, acerca del estilo de vida, trabajo y la subjetividad en el contexto de la caña de azúcar en Brasil. Se analizan las publicaciones científicas de los años 20002010, en portugués, disponibles en la biblioteca electrónica SciELO y tesis en la base de datos de CAPES. El análisis, desde una perspectiva foucaultiana, se ha estructurado en tres áreas: la ciencia y la vida cotidiana; resistencia y sumisión; subjetividad / subjetivación. Llegamos a la conclusión que la mayoría de estas producciones están vinculadas a las tradiciones críticas, la objetivación de los sujetos cambia de las descripciones de la pasividad y las prácticas autónomas de resistencia; estudios sobre la subjetividad no son parte de las publicaciones sobre la industria de la caña de azúcar. Indicamos la necesidad de ampliar estos estudios en psicología desde la perspectiva de la epistemología política.

Palabras clave: Ciencias humanas y sociales, poder-saber, sector de la caña de azúcar; subjetividad.

\section{Introdução}

Este estudo aborda a produção de conhecimentos científicos sobre os modos de vida que se desenvolvem em torno das atividades culturais e econômicas envolvendo os complexos sucroalcooleiros no Brasil. A partir de uma perspectiva da Psicologia Social que se volta à problematização dos modos de subjetivação na sua articulação com os discursos científicos, analisamos a produção de conhecimentos das ciências humanas e sociais que discutem temas concernentes à subjetividade, saúde e trabalho em tais contextos sucroalcooleiros. A justificativa para esse trabalho reside na lacuna existente entre a amplitude das atividades produtivas do setor no Brasil, em contrapartida à escassa produção acadêmica no campo das Ciências Humanas e Sociais e, especificamente, no campo da Psicologia. Neste sentido, nosso objetivo geral é 
identificar e discutir o que se tem produzido no Brasil, no campo acadêmico das ciências humanas e sociais, a respeito dos contextos de vida e trabalho e modos de subjetivação em tais complexos de produção.

A partir disso, buscamos analisar como as relações de saber/poder se explicitam neste campo de estudos acadêmicos, assim como questionar em que medida certas relações de poder permanecem invisíveis e intocadas no interior mesmo desta produção científica. Objetivamos ainda identificar os atores sociais presentes nessas produções, e discutir os modos como os conhecimentos das ciências humanas e sociais posicionam e objetivam os sujeitos desses processos, evidenciando ou não, suas possibilidades de resistência. Por fim, este trabalho também objetiva problematizar a relação das ciências humanas e sociais com os processos de subjetivação de certos atores sociais presentes nos respectivos contextos, produzindo subsídios para a interlocução da Psicologia Social com as problemáticas desse contexto sócio-cultural e econômico.

\section{Materiais e métodos}

Para a análise dos saberes científicos produzidos no campo das ciências humanas e sociais no Brasil acerca do campo da cultura sucroalcooleira estabelecemos alguns critérios de seleção do material a ser investigado. Primeiro, escolhemos selecionar trabalhos publicados em língua portuguesa em uma biblioteca eletrônica e em uma base de dados científicos entre os anos de 2000 e 2010: respectivamente o Scielo ${ }^{1}$ e o Banco de Teses da CAPES ${ }^{2}$. Tal escolha levou em conta o aspecto satisfatoriamente representativo que esses ambientes virtuais possuem em relação à produção científica nacional. Dessa maneira, delimitamos a produção científica a ser analisada aos artigos e teses de doutorado locados nos sites referidos, excetuando outros gêneros de produção do conhecimento científico como dissertações de mestrado e livros. A delimitação dessas materiais, bem como a exclusão de livros e dissertações de mestrado, também foi operada tendo em vista questões acessibilidade. $O$ material analisado foi acessado por meio de três termos descritores compreendidos como aqueles que melhor exaurem a busca conceitual de trabalhos científicos relacionados a este campo cultural e econômico: "cana-de-açúcar", "agroindústria canavieira" e "canavieira(o)",

Os trabalhos arrolados sob esses três termos descritores foram selecionados, obedecendo-se aos seguintes critérios: a) artigos e teses de doutorado categorizados exclusivamente entre as ciências humanas 
e sociais, excetuando assim aqueles ligados às ciências biológicas e agrárias, com exceção dos trabalhos nestes campos que tematizem questões abertamente caracterizadas como pertencentes às ciências humanas e sociais; b) artigos e teses de doutorado relacionados ao debate sobre processos de constituição de subjetividade, e aos temas ligados ao trabalho, à saúde e ao cotidiano das comunidades em questão; c) artigos e teses de doutorado que discutem as formas de poder e resistência no contexto da cultura canavieira no Brasil.

\section{Resultados}

\section{Biblioteca Eletrônica Scielo Brasil}

Com base nos critérios de seleção do material descritos, cinco artigos da biblioteca eletrônica Scielo foram selecionados para esta análise. Nota-se que os temas "trabalho" e "saúde" dominam essas produções. Destacam-se questões concernentes ao universo dos trabalhadores safristas cortadores de cana, com predominância das análises feitas no estado de São Paulo ${ }^{4}$. Percebe-se a ausência de produções interessadas nos temas dos processos de subjetivação nesse contexto.

O trabalho de Alves (2006) está interessado em responder à questão pontual das razões da morte dos cortadores de cana. Seu estudo está circunscrito à região canavieira do estado de São Paulo, e não levanta questões concernentes aos trabalhadores e comunidades que sustentam esta indústria na entressafra. Em resumo, Alves procurar entender como as condições de trabalho às quais são submetidos esses cortadores de cana incidem na debilidade da saúde dos mesmos, ocasionando um grande número de complicações orgânicas como câimbras, falta de ar, desmaios, dores no corpo, e também num grande número de óbitos. Alves (2006) acredita que "com todo o detalhamento da atividade do corte de cana, fica fácil entender por que morrem os trabalhadores rurais cortadores de cana em São Paulo: por causa do excesso de trabalho" (p. 96). Alves conclui seu artigo apontando para as possibilidades de reestruturação das relações capital-trabalho no setor canavieiro paulista, considerando como fundamental para isso o fim do pagamento por produção. $\mathrm{O}$ autor também cogita acerca da possibilidade de mecanização da colheita da cana, sugerindo o exemplo de outros contextos onde as articulações entre "Estado, Capitalistas e Trabalhadores" produziram resultados eficazes na humanização dessas relações de trabalho. Nos casos apontados por Alves, esses contextos souberam intercalar o uso de tecnologia na colheita da cana com políticas concomitantes de reforma agrária, proporcionando produção 
de renda aos trabalhadores que antes abasteciam a demanda do corte manual da cana.

O trabalho de Novaes (2007) segue objetivos idênticos ao anteriormente descrito, no que diz respeito a apresentar um quadro das condições adversas de trabalho dos cortadores de cana, assim como refletir acerca das principais complicações orgânicas que essa atividade impõe a tais trabalhadores. Sua pesquisa ocorre no contexto paulista, e confere assento aos trabalhadores rurais pertencentes aos ciclos migratórios de origem no nordeste brasileiro. No entanto, Novaes apresenta um interessante leque de recursos argumentativos, que dá características distintas ao seu trabalho. Como reforço à argumentação acerca da precariedade e dos riscos da atividade do corte de cana, Novaes (2007) lança mão do uso de imagens fotográficas produzidas pelo próprio autor durante o atendimento hospitalar recebido por um trabalhador acidentado. Em seu discurso de denúncia às condições desfavoráveis de trabalho nos canaviais paulistas, além do recurso do uso de imagens fotográficas, o autor efetua a mescla entre o discurso científico e a metáfora poética, que compreende como uma "interpretação da realidade" (p. 174). Além disso, Novaes (2007) lança mão de entrevistas semi-estruturadas com os trabalhadores em questão, para destacar nessas falas os modos como os cortadores de cana teriam sido "socializados" (p.171) no árduo trabalho dos canaviais.

O trabalho de Rumin e Schmidt (2008) é o primeiro daqueles que estamos descrevendo que não toma os cortadores de cana como objeto de estudos, mas os trabalhadores fabris do complexo de produção de álcool e açúcar. Localizado no campo dos estudos da saúde do trabalhador, o estudo de Rumin e Schmidt está interessado em compreender como a organização do trabalho em uma determinada usina sucroalcooleira incide diretamente sobre a saúde dos trabalhadores aí presentes. Os autores se guiam pelo referencial teórico da Psicodinâmica do Trabalho de Christophe Dejours. $\mathrm{O}$ artigo consiste fundamentalmente da avaliação de material coletado a partir de observação direta no ambiente de trabalho e de entrevistas semidirigidas junto a vinte $\mathrm{e}$ dois trabalhadores. Rumin e Schmidt concluem que a organização do trabalho na referida usina, sobretudo no campo das materialidades como riscos físicos, químicos e biológicos, produzem efeitos danosos aos trabalhadores que vão desde doenças a estresse psicológico. A partir das entrevistas realizadas com o grupo de trabalhadores mencionado, os autores também concluem que estes desconhecem a legislação e as teorias acerca dos 
acidentes de trabalho, e em função disto tornam-se assujeitados pela "violência constituída discursivamente pela organização do trabalho" (Rumin \& Schmidt, 2008, p. 65). As resistências presentes entre os trabalhadores recebem alguma atenção, mas são interpretadas à luz do referencial teórico adotado como uma "ordem psíquica por meio da qual ele [o trabalhador] tenta se livrar da ordem fisiológica" (Rumin \& Schmidt, 2008, p. 59).

O quarto trabalho coletado na base de dados Scielo e aqui analisado também elege como objeto de estudos a saúde dos trabalhadores rurais cortadores de cana. Em consonância com os estudos de Alves e Novaes, Rumin, Navarro e Perioto (2008) também objetivam compreender como a estruturação do trabalho de corte de cana incide nos problemas relacionados à saúde desses trabalhadores. Seu estudo segue referenciais marxistas, e os dados foram coletados por meio de observações diretas do trabalho e por entrevistas semidirigidas. Duas peculiaridades marcam o trabalho de Rumin, Navarro e Perioto. A primeira diz respeito a uma longa caracterização da agroindústria canavieira, assim como as recentes transformações ocorridas no setor de produção agroindustrial em sua relação com os novos movimentos macroeconômicos. Essa descrição visa ajudar a compreensão do aumento da exigência de produtividade do setor, que terá conseqüências diretas nos modos de organização do trabalho de corte da cana. Outra peculiaridade é a presença constante no artigo, de recortes de falas dos trabalhadores. Além de concluírem acentuando os agravos físicos e "psíquicos" ocasionados aos cortadores de cana pelo modo de organização cruel deste trabalho, os autores desejam esboçar saídas para a situação. Entre as propostas políticoeconômicas sugeridas em seu artigo, Rumin, Navarro e Perioto (2008) compreendem que à universidade (isto é, à produção científica) cabe a necessidade de "gerar conhecimento capaz de eliminar, ou ao menos minimizar" (p. 205) os efeitos danosos da organização do trabalho de corte de cana.

Dos artigos que nos propomos analisar aqui, o de Tavares e Lima (2009) é o mais destoante do conjunto. Embora também se ocupe da situação dos cortadores de cana, é produzido a partir do contexto paraibano, e segue outra metodologia, não fazendo uso de recursos como entrevistas ou observações de campo. Operando a partir de categorias conceituais marxistas, Tavares e Lima desejam responder a duas questões fundamentais: por que no setor canavieiro os trabalhadores da indústria recebem salário por tempo, enquanto os trabalhadores do campo recebem por 
produção; e por que certas leis trabalhistas que deveriam proteger os trabalhadores do campo, acabam por produzir maior exploração dos mesmos. Discorrendo acerca das transformações na economia mundial ocorridas com a emergência do neoliberalismo a partir da década de 1990 , as autoras confrontam a ideia de "liberdade" propagandeada como subjacente ao trabalho por produção. Dessa forma, concluem que as imposições do "capital" relativizam o papel do próprio Estado enquanto instância reguladora das relações trabalhistas, e otimizam os processos de exploração do trabalhador, sobretudo daqueles ligados aos modos de assalariamento por produção, como no corte de cana.

Explicitamos a ênfase conferida pelas pesquisas das ciências humanas e sociais junto à agroindústria canavieira no Brasil dada aos cortadores de cana, isto é, aos trabalhadores rurais marcados pela relação sazonal com este setor de produção econômica. Tais trabalhos buscam discutir majoritariamente questões relacionadas às condições de trabalho e seu impacto sobre a saúde desses trabalhadores. Em apenas um artigo os trabalhadores fabris ligados a este setor são a referência para a produção do conhecimento, e neste artigo também se privilegia a discussão da relação trabalho/saúde. É possível pontuar uma ausência de debates acerca dos processos de subjetivação. Nos trabalhos aqui revisados, a subjetividade é somente lugar de "sofrimento psíquico". Nenhum dos trabalhos aqui analisados toma as comunidades de trabalhadores ligados perenemente à economia canavieira como objeto de estudos. Esses trabalhos demonstram a centralização das pesquisas nas ciências humanas relacionadas com a agroindústria canavieira no contexto paulista. No que diz respeito aos aspectos propriamente metodológicos, percebe-se a interessante presença da documentação fotográfica como recurso de argumentativo na construção do saber das ciências humanas acerca do campo. Além disso, também há certo privilégio aos modos convencionais de coleta de dados operados por meio de observações de campo e de entrevistas semidirigidas, como se pode perceber em pelo menos três dos trabalhos aqui resumidos.

\section{Banco de teses da CAPES}

Com base nos critérios de seleção do material já explicitados, duas teses de doutorado do banco de teses da CAPES foram selecionadas para esta análise.

O trabalho de Silva (2000) elege como público-alvo de estudos as nuances do universo infantil na cultura canavieira pernambucana. $\mathrm{O}$ problema que move sua discussão consiste em saber "se o 
capitalismo, com toda sua carga destrutiva do trabalho alienado, conseguiu suprimir total ou parcialmente o tempo de lazer/lúdico das crianças canavieiras" (p. ix). Silva orienta seus estudos à luz do referencial teórico inspirado nos pressupostos da Sociologia da Vida Cotidiana de Henri Lefebrve, e opera a construção de dados a partir de inserções em movimentos de natureza política e sindical de comunidades canavieiras pernambucanas, assim como a partir de visitas regulares às próprias usinas, engenhos e comunidades canavieiras. Seu trabalho faz uso de documentação fotográfica, poesia, desenhos, observação, oficinas de jogos e documentos diversos. $\mathrm{O}$ estudo de Silva conclui que o tempo lúdico das crianças canavieiras, apesar de ser exíguo e em grande parte submetido às dinâmicas trabalhistas impostas pelo capital, é um espaço de "resistências e rebeldias à ordem alienante estabelecida" (p. ix). Chama-nos a atenção no trabalho de Silva a liberdade nos modos de expressão, com farto uso do pronome em primeira pessoa, assim como a interlocução da escrita nos moldes tipicamente considerados como "científicos" com elementos da poesia, como mencionados acima, somados a questões de ordem biográfica, assumidamente presentes em seu texto como motivadores de sua pesquisa e discussão acerca do universo infantil no contexto canavieiro.

O extenso trabalho de Dabat (2003) segue a linha da problematização, centrando-se no conceito de "morada de engenho" aplicado por algumas correntes literárias aos locais de residência dos trabalhadores rurais ligados ao campo canavieiro após o período da escravidão. Seu objetivo é confrontar esse conceito de morada de engenho presente tanto nessa literatura com as memórias coletivas dos próprios atores sociais implicados, isto é, com os trabalhadores que residiram nas "moradas de engenho". Dabat centraliza suas atenções nos trabalhos literários de José Lins do Rego e Gilberto Freire, nos âmbitos da literatura e da academia, respectivamente. Em confronto com a memória coletiva revirada por meio de entrevistas e de depoimentos de antigos "moradores de engenho", a autora busca problematizar o ar "bucólico" presente nessas narrativas, que tendiam a suavizar a crueldade das relações trabalhistas naquele período. Conforme Dabat, esses autores contribuíram para a consolidação da ideia, no senso comum, de que a "morada de engenho" haveria representado uma situação de estabilidade das relações trabalhistas entre empregadores e empregados neste setor, responsável por mediar historicamente a transição da escravidão à proletarização completa 
desses trabalhadores rurais. Conforme Dabat (2003), em contraposição a essas versões tornadas oficiais, "os depoimentos [dos moradores de engenho] confirmam sem equívoco as outras fontes sobre condições de vida extremamente miseráveis e relações de trabalho marcadas pela brutalidade" (p. 29). Questões como o completo abandono do estado, exemplificadas no descaso concernente à saúde e educação, e as imposições verticais nas relações trabalhistas ganham foco na reconstrução das memórias que os trabalhadores fizeram do tempo da "morada de engenho". Seu estudo adota o marxismo como referencial teóricometodológico, e lança de mão de entrevistas individuais como recurso para coleta de dados.

\section{Discussão}

\section{Ciência e cotidiano no mundo da cana}

Os saberes científicos implicados em nossa análise, relacionados com o campo da cultura canavieira no Brasil, provêm da Economia, da Psicologia, da Sociologia e da História, com a presença também da Engenharia Agronômica. A maior parte dos trabalhos da base de dados Scielo situa-se no contexto da agroindústria canavieira paulista, enquanto os dois trabalhos do banco de teses da CAPES situam suas pesquisas no nordeste de Brasil. Grande parte dos estudos aqui analisados (Silva, 2000; Dabat, 2003; Alves, 2006; Novaes 2007; Tavares \& Lima, 2009) pode ser compreendida como ligadas à uma tradição científica de pretensões críticas, com forte acento na denúncia de aspectos políticos e econômicos ligados às más condições de vida e de trabalho das comunidades e trabalhadores ligados ao complexo canavieiro no Brasil. Alguns destes estudos tomam o campo da saúde como viés teórico-metodológico (Novaes, 2007; Rumin \& Schmidt, 2008; Rumin, Navarro \& Perioto, 2008), embora também se constituam a partir daí como discursos críticos das relações entre empregadores e empregados neste setor de produção econômica. Ao lado de uma relativa diversidade das concepções teóricas que fundamentam esses estudos, há certa ênfase nos métodos de produção de dados ligados à observação participante e às entrevistas semiestruturadas. Os trabalhos aqui analisados também lançam mão de diversos recursos discursivos, verbais e não-verbais, que vão desde a poesia à documentação fotográfica (Novaes, 2007), desde a narrativa autobiográfica (Silva, 2000) até materiais das ciências médicas (Novaes, 2007; Rumin, Navarro \& Perioto, 2008).

Estamos considerando como uma "tradição crítica" àqueles modos de 
produção epistemológica datados por Foucault (2011) a partir dos séculos 15 e 16, e identificados, inicialmente, como formas de resistência às injunções do poder pastoral, caracterizados como uma suspeita da arte de governar e como recusa em ser governado de certos modos. Conforme Foucault (2011), a crítica "é então, desse ponto de vista, em face do governo e à obediência que ele exige, opor direitos universais e imprescindíveis, aos quais todo governo, qual seja ele, quer se trate do monarca, do magistrado, do educador, do pai de família, deverá se submeter” (p. 4). A crítica seria o movimento pelo qual o sujeito, qualquer que seja o campo epistemológico em questão, se daria o direito de interrogar a verdade sobre seus efeitos de poder e o poder sobre seus discursos de verdade. Nos termos de Foucault (2011), ela teria por função uma forma de "desassujeitamento da política da verdade" (p. 5). No entanto, Foucault problematiza essa tradição crítica, afirmando que a mesma tornou-se pura heteronomia, existindo apenas em relação a outra coisa que não ela mesma: "ela é instrumento, meio para um devir ou uma verdade que ela saberá e que ela não será, ela é um olhar sobre um domínio onde quer desempenhar o papel de polícia e onde não é capaz de fazer a lei”' (p. 2).

Uma das questões capitais que gostaríamos de destacar nesta análise é de ordem política e epistemológica. Como nos lembra Latour (2004), “toda questão epistemológica é, bem por isso, uma questão política" (p. 67). Para este autor, é com pesar que a epistemologia e a política "continuam a nos aparecer como conjuntos sem nenhuma relação, do qual o primeiro não tem mesmo como receber o nome de poder" (p. 63). Dessa maneira, o exercício de perscrutar a "caixa-preta" da atividade científica deve passar necessariamente por uma reflexão acerca das implicações políticas e éticas dessa atividade. Os trabalhos aqui analisados assumem posicionamentos políticos explícitos, cuja pretensão consiste em fazerem-se vozes críticas, sobretudo em relação aos dilemas dos trabalhadores ligados à cultura canavieira, tanto sazonal quanto perenemente. Alguns desses trabalhos chegam a replicar certos binarismos consagrados numa literatura de pretensões críticas, identificando a posse e o mau uso do poder ora nas mãos do Estado (Dabat, 2003; Tavares, 2009), ora nas mãos dos capitalistas e empresários (Silva, 2000 e Alves, 2006).

Marcadas por análises das relações de poder identificadas com o que Foucault (2010a) chamou de "modelo jurídicodiscursivo", tais avaliações tornam-se insuficientes e parciais, pois concomitante ao movimento de crítica à exploração e ao abuso de poder nas relações entre 
empregados e trabalhadores da cultura canavieira, tais produções científicas furtam-se de avaliações acerca do papel exercido pela própria ciência na produção do aparato tecnológico responsável por maximizar as dinâmicas produtivas neste setor. O policiamento científico dos trabalhos das ciências humanas e sociais que ora analisamos, nestes casos, caracteriza-se por uma profunda relação de heteronomia que identifica alvos passíveis de crítica sempre exteriores a si mesmos. Embora não consistam em objeto direto de análise neste trabalho, nessa pesquisa constatou-se que a produção científica relacionada com a economia canavieira no Brasil consiste majoritariamente de pesquisas no campo do melhoramento genético e no aprimoramento do aparato técnico-industrial ligado à produção de álcool e açúcar. Rumin, Navarro e Perioto (2008) chegam a mencionar a importância da produção técnico-científica para a modernização do complexo canavieiro no Brasil, mas sem problematizá-la. Citando uma pesquisa realizada anteriormente, tais pesquisadores afirmam que

a crescente e cada vez mais significativa participação do conhecimento técnicocientífico no delineamento do ritmo e da intensidade do processo de modernização do complexo agroindustrial sucroalcooleiro, a partir da incorporação de novas tecnologias e equipamentos no processo de produção, nas diferentes etapas da cultura e na industrialização da cana, vem dando uma nova tônica ao processo de valorização e reprodução do capital (Thomaz Júnior, citado por Rumin, Navarro \& Perioto, 2008, p. 196).

Novaes (2007), embora também permaneça no campo da constatação sem problematização, também percebe que a produção de conhecimento científico tem estado correlacionada com a modernização e a expansão dos mercados canavieiros, sobretudo a partir da contratação de pessoal especializado nos diferentes saberes científicos forjados nas universidades. Interessante observar que para Novaes, tais implementações dos saberes científicos são o "efeito" da expansão dos mercados canavieiros, e não sua causa. Conforme sua avaliação,

tanto a implantação de novas unidades de produção como a modernização das usinas em operação provocam mudanças na dinâmica do mercado de trabalho da cana. Um dos seus efeitos é a contratação de mão-de-obra qualificada (agrônomos, técnicos agrícolas, engenheiro químico, contador, engenheiro de produção, psicólogos e outros), formados nas universidades e nos centros tradicionais de pesquisa [...] (Novaes, 2007, p. 170). 
Dos trabalhos aqui analisados, apenas Dabat (2003), em sua tese de doutorado, apresenta problematizações acerca da relação entre o conhecimento científico e o campo da cultura canavieira, ao questionar as perspectivas com as quais o trabalho de Gilberto Freire contribuiu para a produção de imagens das relações trabalhistas no universo canavieiro, que destoavam das narrativas dos próprios “moradores de engenho". Em sua maioria, entretanto, a produção científica no campo das ciências humanas e sociais ocupada com as questões desse universo ainda sustenta perspectivas fetichistas em relação à própria natureza do trabalho da ciência. Consideramos que a maior parte dessas produções, em seu afã criticista e libertário, termina por isentar a ciência de suas as implicações éticas e políticas da relação com o setor canavieiro, assim como reproduzem os esquemas e promessas de "redenção-salvação" (Garcia, 2002) próprias de um poder de tipo pastoral, agora laicizados nas "evidencias" da elucubração científica.

\section{Resistência e submissão: afinal, quem são esses "sujeitos explorados"?}

Foucault (2010b) havia apontado para três possibilidades de luta no campo social, a saber: (1) contra as formas de dominação étnica, social e religiosa; (2) contra as formas de exploração que separam os indivíduos daquilo que eles produzem; (3) e contra aquilo que liga o indivíduo a si mesmo e o submete, desse modo, aos outros, isto é, contra a submissão da subjetividade (p. 278). Esses tipos de lutas sociais, segundo este autor, podem ser encontrados isolados uns dos outros. No entanto, conforme Foucault, mesmo quando essas lutas estão misturadas, uma delas, na maior parte do tempo, prevalece. Este autor adverte que cada tipo de luta mantém relações complexas e circulares com outras formas (Foucault, p. 2010b). Conforme uma cronologia (não muito consensual) presente em autores interessados em categorizações temporais, os trabalhos do "último Foucault" (Castelo Branco, 2001; Veiga-Neto, 2003; Ferreira, 2009; Revel, 2004) estariam voltados especialmente para as lutas de tipo (3), isto é, àquelas contra o governo da subjetividade.

Seguindo esta organização, é possível dizer que na produção científica que ora analisamos, as lutas de tipo (2) ou seja, aquelas estabelecidas contra as formas de exploração econômica -, são o tópico privilegiado de estudos ${ }^{5}$. É no contexto dessas lutas que a produção das ciências humanas e sociais operam modos de objetivação dos sujeitos aí implicados. 
Tais objetivações são heterogêneas, o que não quer dizer que sejam contraditórias. Oscilam entre a descrição de sujeitos passivos e assujeitados em sua conduta, e sujeitos marcados por práticas autônomas de resistências. Rumin, Navarro e Perioto (2008) descrevem os trabalhadores de usina como sujeitos "coagidos a trabalhar" (p. 199), como “superexplorados” (p. 203) e como vítimas de uma "dominação de classe" (p. 205). Para Novaes (2007), a exploração do trabalho nos canaviais tem como pano-de-fundo o fato dos cortadores de cana terem sido "socializados desde criança em meio ao trabalho duro no nordeste" (p. 171). Conforme Tavares (2009), tais trabalhadores têm sua liberdade "caçada pelo capital neoliberal" (p. 173), e quando resistem, o fazem em nome de "necessidades primárias" (p. 176). Conforme Rumin e Schmidt (2008), os trabalhadores de usina "desconhecem seus direitos" (p. 62), razão pela qual são constantemente "ludibriados por seus patrões" (p. 63), além de serem totalmente "subjugados às relações de poder no trabalho" (p. 65).

Não obstante as descrições acima apresentadas, o tema da resistência também tem certo lugar na produção de conhecimentos científicos acerca da cultura canavieira no Brasil. Entre outros objetivos, os artigos e teses de doutorado aqui analisados ocupam-se com a questão de como os sujeitos implicados nesses contextos, sobretudo os trabalhadores, resistem às assimetrias impostas pela relação com seus empregadores. A temática da resistência aparece aí de modo fragmentado e heterogêneo, de acordo com os interesses de cada pesquisador. Convém recordar que para Foucault, não há relações de poder sem a correlata ocorrência da resistência, e que a ocorrência das resistências tem um caráter profundamente heterogêneo.

$\mathrm{Na}$ produção científica que ora analisamos os atores sociais "trabalhadores rurais do corte de cana", e os "moradores das agrovilas", são caracterizados, em certa medida, como sujeitos de resistência. Alves (2006), no contexto de sua busca pelas razões das mortes dos cortadores de cana, evidencia as resistências institucionais de tais trabalhadores no campo sindical e grevista, fazendo questão de acentuar as conquistas perenes desses trabalhadores obtidas em função de sua resistência organizada neste campo sindical. De acordo com Novaes (2007), o próprio processo de "socialização" (p. 171), marcado pelas dificuldades na vida e no árduo trabalho da agricultura no nordeste, se constitui como um fator de resistência às duras exigências físicas impostas pelo trabalho no corte de cana. Em Rumin e Schmidt (2008) o tema da resistência aparece, à luz da Psicodinâmica 
do Trabalho de Christophe Dejours, nos moldes intrapsíquicos, em torno do construto "subversão", como modo de resistência individual frente às demandas fisiológicas do trabalho de usina. Em Silva (2000), o tema da resistência aparece relacionado ao lúdico e ao universo infantil das comunidades canavieiras, uma vez que este tempo lúdico é aí concebido como espaço de resistências e rebeldias à ordem alienante estabelecida. Em Dabat (2003) a temática da resistência aparece relacionada à memória coletiva de pessoas e comunidades canavieiras, e à própria produção científica e literária, uma vez que são confrontados os discursos produzidos por essas instâncias com o discurso que os moradores produzem sobre sua relação com as "moradas de engenho".

\section{Subjetividade/subjetivação no contexto canavieiro}

O material selecionado para nossa análise evidencia que os estudos sobre a subjetividade ainda não fazem parte do campo preocupações científicas em sua aproximação ao universo canavieiro. Nem o conhecimento produzido em Psicologia, no diálogo com este campo, leva em conta as questões envolvendo os processos de subjetivação, muito menos os modos de vida das comunidades ligadas a essas dinâmicas culturais e econômicas.
Conforme o material analisado, o universo de produção sucroalcooleira comparece aí majoritariamente como campo de tensões trabalhistas e de exploração econômica. Em contrapartida, o tema da subjetividade aparece perifericamente em alguns desses trabalhos, reduzidos à dimensão do “sofrimento psíquico". Certamente, o modo de objetivação psicológica dos sujeitos presentes nesses contextos se deve às concepções hegemônicas da subjetividade como interioridade, pelo menos no campo da Psicologia. Para Rumin, Navarro e Perioto (2008), por exemplo, o excesso de trabalho a que são submetidos os cortadores de cana "atua sobre o psíquico do trabalhador" (p. 202). Ainda conforme tais autores, mesmo quando o excesso de trabalho não lesiona fisicamente os cortadores, ele "deixa marcas por meio do sofrimento psíquico", além de "invadir o espaço subjetivo" desses sujeitos (p. 205). Para Rumin e Schmidt (2008), um dos efeitos danosos ocasionados pela carga de trabalho está no campo do "psíquico" (p. 60), enquanto "subordinação da saúde e da subjetividade dos trabalhadores" aos ditames do lucro imposto pelo capital (p. 65).

A partir dessas afirmações, pode-se concluir que a produção das ciências humanas e sociais acerca do contexto canavieiro no Brasil, além de não interessar-se, ao menos por hora, nas 
questões envolvendo os processos de subjetivação, sustentam uma concepção da subjetividade marcada pelas cisões e dicotomias entre saúde física e saúde psíquica, além de sustentar concepções do "psiquismo" e da "subjetividade" como elementos anistóricos constitutivos da essência humana. A subjetividade ou o psiquismo, tratados aí sem muita diferenciação conceitual, constituem-se como "lugares de sofrimento" e como "alvos internos" das violências externas do capital e do trabalho. Há nessas abordagens uma maneira de descrever o campo da subjetividade como um "dentro", próprio da interioridade, oposto a um "fora", próprio da exterioridade, que é alvo do sofrimento físico ocasionado pela brutalidade do trabalho canavieiro, seja no corte dos canaviais, seja no chão de fábrica das usinas. Mesmo quando atrelada ao conceito dejouriano de "subversão", a questão subjetividade permanece circunscrita à dicotomia saúde física versus saúde psíquica, uma vez que o papel da subversão (interna) consistiria em "construir uma ordem psíquica por meio da qual ele [o trabalhador] tenta se livrar da ordem fisiológica" [externa] (Rumin \& Schmidt, 2008, p. 59).

Embora não esteja entre os objetivos deste trabalho empreender uma longa discussão acerca das concepções de subjetividade no campo das ciências humanas e sociais em geral, nossa intenção de momento consiste em problematizar a objetivação dos sujeitos presentes na pesquisa que ora analisamos como “sujeitos psicológicos". Nesta problematização, nos utilizamos da ideia de "genealogia da subjetivação" (Rose, 2001) assim como do conceito de "dobra", extraído por Rose do trabalho de Gilles Deleuze. Segundo Rose (2001), o propósito fundamental de uma genealogia da subjetivação seria o de "escrever a história dos regimes contemporâneos do eu" (p. 33). Essa tarefa se diferencia das tentativas filosóficas e literárias de descrever as mudanças das ideias sobre a pessoa, assim como de uma história da pessoa considerada como entidade psicológica e descrita por diferentes sistemas psicológicos. Rose também diferencia a genealogia da subjetivação das grandes narrativas sociológicas que associam as formas cambiantes da subjetividade às grandes transformações sociais e culturais no Ocidente, tais como as transições da sociedade tradicional para a modernidade e do feudalismo para o capitalismo. Rose (2001) insiste que um projeto de genealogia da subjetividade deve levar em consideração o conjunto de práticas pelas quais as pessoas são compreendidas e pelas quais se age sobre elas. 
Segundo Rose (2001), privilegiar o domínio das práticas consiste em perguntar-se pelos "dispositivos de produção de sentido" (p. 36) inventados por diferentes instituições sociais. É perguntar-se pelas "tecnologias humanas" (p. 39) enquanto meios de governo e de orientação da conduta de uns seres humanos por outros. É perguntar-se sobre a fonte de "autoridade" (p. 40) que algumas instituições e indivíduos exercem sobre outros. É perguntar-se sobre as "teleologias" (p. 41), isto é, acerca de quais finalidades ou formas de vida embasam a ação sobre a ação dos outros. É perguntarse sobre que "estratégias" (p. 42) ligadas a objetivos morais, sociais ou políticos mais amplos servem à regulação das pessoas nos diversos campos de atividade. É desse emaranhado de relações e de jogos de força - em contraponto a qualquer noção de interioridade a priori a esses jogos de força - que emerge a metáfora da "dobra" para se falar da subjetividade.

Interrogar as práticas presentes no universo de relações de habitação e de trabalho do contexto canavieiro seria a tarefa primordial para uma genealogia da subjetivação nesse contexto, assim como perguntar sobre como tais práticas agenciam e produzem sujeitos de um determinado tipo. Conforme Hüning e Guareschi (2009), isso implica numa mudança profunda de atitude por parte dos “especialistas". Primeiro, com a produção de outras estratégias epistemológicas que focalizem as práticas que ora enfatizamos, e pela inclusão dos "saberes marginais" (Hüning e Guareschi, 2009) oriundos do cotidiano das pessoas. Segundo, pela possibilidade de tornar o conhecimento científico como "alvo de intervenção" e "passível de problematizações", que foi aquilo que nos interessou neste trabalho.

\section{Considerações finais}

A que se prestam essas problematizações? Em primeiro lugar, é importante observar que "a verdade não existe fora do poder" (Foucault, 1979, p. 12), tampouco as verdades científicas que compuseram o conteúdo dessas problematizações. Nesse sentido, a própria verdade produzida pelo tipo de análise aqui empreendida precisa estar sob constante vigilância crítica. As verdades aqui problematizadas, enquanto representantes de certo tipo de discurso produzido a partir de rituais, balizado por regras e legitimado por instituições, fazem parte daquilo que Foucault (1979) chamou de "economia política da verdade" (p. 13). Em sociedades como a nossa, dizia Foucault, a "verdade" é centrada na forma do discurso científico e nas instituições que o produzem. Portanto, as problematizações aqui empreendidas visam enriquecer e 
aprofundar o debate acerca desta economia política da verdade sobre certos grupos humanos, realizadas nos ambientes de produção de conhecimento científico. Pretendemos também pontuar a relevância da temática da constituição da subjetividade e dos modos de vida no contexto da cultura canavieira no Brasil e a necessidade de desenvolvimento de mais estudos no campo da Psicologia Social e das Ciências Humanas e Sociais, que ampliem a produção acadêmica para além dos aspectos econômicos e tecnológicos do setor. Ainda que se considere a relevância econômica da atividade sucroalcooleira que impulsiona altos investimentos em pesquisas voltadas ao seu desenvolvimento tecnológico, é preciso também atentar para os sujeitos que compõem tais universos. Nesse sentido, não nos cabe prescrever modos de abordar ou pesquisar tais questões, mas assinalar a quase invisibilidade das mesmas até o momento no cenário acadêmico, indicando a importância de que estas sejam pensadas a partir do que Latour (2004) chamou de epistemologia política, fazendo a "análise explícita dos poderes entre ciências e políticas" (p. 376).

Ao indicarmos a necessidade de ampliação dos estudos sobre os modos de subjetivação nos contextos em questão, destacamos como compromisso da pesquisa, manter-se atenta aos efeitos de poder desses discursos. Desse modo, nossa tarefa se inscreve simultaneamente em um projeto de genealogia dessas relações de poder, e se constitui, como apontava Foucault (2005), como um projeto de “anticiência” (p. 14), na medida em que põe em cheque o status de uma verdade e de um discurso unitário produzidos nos âmbitos da ciência acerca de determinadas populações.

\section{Nota}

${ }^{1}$ Scientific Eletronic Library Online. Cf. o sítio www.scielo.org

2 Coordenação de Aperfeiçoamento de Pessoal de Nível Superior. Cf. o sítio http://capesdw.capes.gov.br/capesdw/

3 O termo descritor "sucroalcooleiro" também foi utilizado na seleção do material. Contudo, uma vez que os resultados obtidos com esse descritor coincidem com os obtidos com o descritor “agroindústria canavieira", decidimos excluir aquele desta relação de termos descritores.

${ }^{4}$ Dos cinco artigos aqui analisados, quatro deles realizaram a coleta de dados em 
usinas e comunidades do estado de São

Paulo.

5 Não obstante esta observação, não consideraríamos equivocado caracterizar também as lutas contempladas no material que ora analisamos como as de tipo (1), ou seja, como lutas contra formas de dominação social.

\section{Referências}

Alves, F. (2006). Por que morrem os cortadores de cana? Saúde $e$ sociedade. v. 15 , n. 3, p. 90-98, setdez

Castelo Branco, G. (2001). As resistências em Michel Foucault. Trans/form/ação. vol. 24. n. 1, Marília

Dabat, C. P. Y. R. (2003). Moradores de engenho: estudos sobre as relações de trabalho e condições de vida dos trabalhadores rurais da zona canavieira de Pernambuco, segundo a literatura, a academia e os próprios atores sociais. Departamento de História da Universidade Federal de Pernambuco, Recife (Tese de Doutorado)

Ferreira, A. L. (2009). A psicanálise e a psicologia nos ditos e escritos de
Michel Foucault. In: Hüning, S. M.; Guareschi, N. M. de F (2009) (orgs.). Foucault e a psicologia. Porto Alegre: EDIPUCRS

Foucault, M. (2005). Em defesa da sociedade: curso no Collège de France (1975-1976). São Paulo: Martins Fontes

Foucault, M. (2010a). História da sexualidade: a vontade de saber. Tradução de Maria Tereza da Costa Albuquerque e J. A. Guilhom Albuquerque, São Paulo: Graal, vol. 1 Foucault, M. (1979). Microfísica do poder. Organização e tradução de Roberto Machado, São Paulo: Graal

Foucault, M. (2011). O que é a crítica [Crítica e Aufklärung]. Disponível em: www.vsites.unb.br, acesso em $01 / 11 / 2011$

Foucault, M. (2010b). O sujeito e o poder. Dreyfus, H. L.; Habinow, P. Michel Foucault: uma trajetória filosófica: para além do estruturalismo e da hermenêutica. $2^{\mathrm{a}}$ edição, tradução de Vera Portocarrero e Gilda Gomes Carneiro, Rio de Janeiro: Forense Universitária

Foucault, M. (2010c). Poder e saber. Ditos e escritos: estratégia, poder-saber. $2^{\mathrm{a}}$ 
edição, tradução de Vera Lúcia Avellar Ribeiro, Rio de Janeiro: Forense Universitária, vol. IV

Hüning, S. M.; Guareschi, N. M. de F. (2009) (orgs). Efeito Foucault: desacomodar a psicologia. Foucault $e$ a psicologia. Porto Alegre: EDIPUCRS

Latour, B. (2004). Políticas da natureza: como fazer ciência na democracia. Tradução de Carlos Aurélio Mota de Souza, Bauru: EDUSC

Novaes, J. R. P. (2007). Campeões de produtividade: dores e febres nos canaviais paulistas. Estudos avançados. v. 21, n. 59, São Paulo

Prado Filho, K. (2009). Para uma arqueologia da psicologia (ou: Para pensar uma psicologia em outras bases). Hüning, S. M.; Guareschi, N. M. de F (2009) (orgs.). Foucault e a psicologia (orgs.). Porto Alegre: EDIPUCRS

Revel, J. (2004). O pensamento vertical: uma ética da problematização. Gros, F. (org.). Foucault: a coragem da verdade. São Paulo: Parábola Editorial

Rose, N. (2001). Como se deve fazer a história do eu. Educação e sociedade. v. 26, n. 1,2001 , pp. 33-57
Rumin, C. R.; Schmidt, M. L. G. (2008). Influências das condições e organização do trabalho de uma indústria de transformação de cana-deaçúcar na ocorrência de acidentes de trabalho. Saúde e sociedade (São Paulo). v. 17, n. 14, p. 56-67

Rumin, C. R.; Navarro, V. L.; Perioto, N. W. (2008). Trabalho e saúde no agrobusiness paulista: estudo com colhedores manuais de cana-de-açúcar da região oeste do estado de São Paulo. Cadernos de Psicologia Social do Trabalho. v. 11, n. 2, p. 193-207

Silva, M. R. da (2000). O assalto à infância no mundo amargo da canade-açúcar: onde está o lazer/lúdico? $O$ gato comeu? Faculdade de Educação da Universidade Estadual de Campinas, Campinas, (Tese de Doutorado)

Tavares, M. A.; Lima, R. O. T. de (2009). A "liberdade" do trabalho e as armadilhas do salário por produção. Katál (Florianópolis). v. 12, n. 2, p. 170-177, jul./dez.

Veiga-Neto, A. (2003). Foucault $e$ a educação. Belo Horizonte: Autêntica

Paulo dos Santos Nascimento: Mestrando em Psicologia pela Universidade Federal 
de Alagoas, membro do grupo de pesquisa

Processos Culturais, Políticas e Modos de

Subjetivação.

E-mail: prteologo@hotmail.com

Simone Maria Hüning: Docente pesquisadora dos cursos de Graduação e de

Pós-Graduação em Psicologia da

Universidade Federal de Alagoas. Líder do

grupo de pesquisa Processos Culturais,

Políticas e Modos de Subjetivação.

E-mail: simonehuning@yahoo.com.br 